examples. This is only the fourth case that has come under my notice during thirty-four years at the hospital. The diagnosis would lie between this disease and that of the hip joint. In the early stage at which both of these cases presented themselves, the sacro-iliac disease bore a striking resemblance to the first stage of "morbus coxæ," with regard to the apparent lengthening and attitude of the limb; but the marked prominence of the iliac spine in front is distinctive. Equally characteristic is the sensation of yielding in the articulation in the act of standing or walking, with sometimes a wriggling movement in progression. These characters taken together, with the absence of any signs or symptoms referable to the hip joint, are diagnostic of sacro-iliac disease.

\section{A SERIES OF CASES OF INJURIES FROM EXPLOSIVES:}

By W. LOUDON STRAIN, M.B.

SURGEON TO ST. JOHY DEL REY MINING COMPANY; LATE HOUSE SURGEON, WESTERN INFIRMARY, GLASGOW.

Doring the last three years I have had to deal with a number of surgical injuries produced by various explosives, and I think them of sufficient interest to warrant their publication, with the short remarks I have to make on each case.

CASE 1.-This case I had to deal with while resident in the Western Infirmary. A strong working man on his way to work picked up a piece of copper tubing and put it in his pocket, intending to make some use of it. On reaching home he proceeded with the help of a darning needle to clean it out, when it exploded in his hand. On admission, it was found that the thumb, fore and middle fingers had been so shattered that amputations had to be performed through the proximal phalanx of the thumb, the middle joint of the forefinger, and at the knuckle of the middle tinger. The man did well. This case is interesting when compared with Case 3. The explosive-fulminate of mercury - was the same in both cases, and the mode of production and damage sustained were almost identical.

CASE 2.-J-J a very old negro, certainly over eighty years of age, was brought to Morro Velho Hospital on Feb. 16th, 1886, terribly injured by the exploding of a quantity of dynamite and percussion caps, with which he was working. The old man's duties were to attach the cap and fuse to the dynamite cartridge. How the accident occurred will never be known. It is estimated that about $5 \mathrm{lb}$. of dynamite and about one hundred caps, with fulminate of mercury, exploded at the old man's feet. On admission he was not unconscious, and complained loudly of pain on any attempt to move him. His left foot, with the lower half of the leg bones, was shattered; the right leg bones were fractured in several places, and almost completely stripped of the soft parts. Beyond scorching of the skin and singeing of his wool, no damage was done to the head, trunk, or upper extremities, all the force of the explosion being exerted on his legs. The poor old fellow survived the removal of his shattered limbs about twelve hours.

This case illustrates how curiously dynamite acts. An inspection of the place where he was working showed a hole about a foot deep and two feet in diameter blown in the ground. The house came down about him, and a gable close by was blown in. The wonder is how he was not blown to atoms. The dynamite with which he was working was on the ground, and he sat on a little bench.

CASE 3.-On Saturday, April 4th, 1886, a Chinaman stole a cap, intending to use the tubing as a ferrule for a stick. Finding it obstructed, he proceeded to clear it out, when it exploded, shattering the thumb, fore and middle fingers of the left hand. Being almost identical with the injuries in Case 1, the amputations were also identical. At the end of a week the stumps were dressed, and looked well. Four days afterwards pain was complained of, and on removing the dressings pus wes found lodging in small quantity in the sheath of the extensor tendon of the middle finger. This was freely incised, and relief followed, but three days afterwards tetanus appeared, and in exactly three weeks from the date of the injury he died asphyxiated.

What caused the tetanus? Had the faulty drainage-the pus lodging as it did in a tendon sheath-anything to do with it? He suffered from chronic tubular nephritis, with aortic regurgitation and dropsy. Had this anything to do with it? The only other Chinaman in the hospital at the time was a man suffering from anæsthetic leprosy, with ulcers. The two were continually together. I merely mention these three things, as I think it not improbable that one or other had to do with the origin of the tetanus. Calabar bean was given in large doses, and continuously, but without benefit. He smoked opium largely.

CAse 4,-In this case I will briefly narrate the injuries sustained by several persons in an explosion which occurred in a mine on April 9th, 1886. After blasting out masses of rock with dynamite the larger pieces are broken up with sledges to a convenient size for conveyance to the surface. On the above date a man was thus engaged, but on striking a mass of rock an explosion occurred, shattering the mass and sending pieces in all directions. Practical miners are at a loss to account for these explosions, which occur at rare intervals; but it is thought that it is due to nitro-glycerine which has exuded from the dynamite during the blasting and remained at the bottom of the "hole" unexploded, and that the sledge coming down on this causes the explosion. This is a matter of importance for the consideration of dynamite makers. By this explosion five persons sustained serious injuries. J-a a Italian, sustained a compound comminuted fracture of the tibia just above the ankle, total destruction of the right eye, and numerous cuts and scratches Ten small fragments of bone were removed from the seat of fracture, and three days afterwards extirpation of the eye had to be performed on account of pain. He made an excellent recovery. C-, a Brazilian, was using the sledge. $\mathrm{He}$ escaped with a simple fracture of the tibia below the knee. T-, a black man, had a severe laceration of his right arm, and across the left side of his throat there was a deep, clean cut, which bared the side of the larynx and also the carotid, which most wenderfully escaped injury. He suffered from profound shock, from which he did not recover for twelve hours. After this, recovery was uninterrupted. A - a black man, had a deep punctured wound in front of his left shoulder. A small artery was wounded, and bled so profusely that I had to cut down and tie it. He suffered a good deal from loss of blood. L-, a black man, was cut across the right eyeball, which was completely destroyed. One curious incident occurred. A man was actually standing on the stone when it exploded. He was thrown for a considerable distance up an inclined surface, but escaped uninjured. All these men were employed close to the place of explosion, besides many others who escaped uninjured.

CASE 5.-Senhor J.F.P-_, a Brazilian, aged about sixty, was terribly injured by the exploding of a dynamite cartridge in his hand. It occurred in the following manner. On a certain day after Easter the terrible fate of Judas the Betrayer is typified or commemorated by the exploding of bombs, firing off rockets, \&c. On this particular occasion dynamite cartridges were used. A short piece of fuse was attached to the cartridge, which was held in the hand until the fuse was seen to have caught fire; then the intention was to throw it away as far as possible for it to explode. The sun shining brightly at the time obscured the sparks flying from the fuse, and thinking it had not caught fire the man held it in his hand until the explosion occurred. I may incidentally remark that the use of dynamite and other dangerous explosives at their religious and other festivals prevails to an alarming extent amongst the Brazilians, and is winked at by the authorities. However, this case has had a very salutary effect in diminishing the nuisance. I was on the spot in about a quarter of an hour, and found the man on the floor in an unconscious state. His right hand was blowr off just above the wrist, and his right eyeball burst; a day or so after $I$ also found both tympanic membranes burst. The amputation of the hand was completed, and a great gash in the palm of the left hand was dressed. The shock was very severe, and required free stimulation for twentyfour hours. On the third day the pain in the destroyed eye was so great that I had to extirpate it. The man's recovery was very slow. Sloughing of the palmar flap occurred and much retarded healing; but after two months he was able to be on horseback again-" a sadder but a wiser man."

This case is of interest in showing the very localised action of the dynamite. The bursting of the eye and

Experienced miners here say that in mines where dynamite is largel used, exuded and unexploded nitro-glycerine is frequently met with, and is a recognised danger in using dynamite for blasting. 
tympanic membranes was induced by the concussion, and beyond scorching his chest and face no other damage was susainted.

Whilst writing the above another explosion has occurred similar to Case 4, but happily without doing serious injury.

$1 \mathrm{am}$ fully aware that no special point of surgery is illustrated in the narration of these cases, and it is not with that intention that I record them. They are interesting and also instructive, in so far as they show a necessity for the greatest care in the manufacturing and using of such dangerous articles. I might say more on this point, but a medical journal is hardly a suitable medium.

Morro Velho, Brazil.

\section{CASE OF VAGINAL HYSTERECTOMY FOR MALIGNANT DISEASE.}

BX FERDINAND A. PURCELL, M.D., SURGEON TO THE CANCER HOSPITAL.

THE case of extirpation of the uterus and its appendages per vaginam which $I$ have to report makes my fourth successful case. A record of the three previous cases appears in a paper by me, and is published in the British Gyncecological Journal (May, 1887, Part ix., p. 60), and was read before the Society on March 9th of this year. I intend to give a full report of this case to show that I have not, with my additional experience, departed from the plan of operation followed in my first three cases.

We may take it for granted that kolpo-hysterectomy is only justifiable when the body of the uterus is cancerous, or when the disease commences near the os internum; and unjustifiable for cancer of the cervix alone, or when the walls of the vagina have been encroached upon, for in the latter condition the surrounding cellular tissue has already been infiltrated, and recurrence after operation will undoubtedly take place in a very short space of time.

Operators are still divided as to the details of the operation: as to whether the peritoneum should be entered in the anterior fornix or the posterior fornix; whether the fundus is to be brought down through the anterior wound or the posterior one; or not to make the uterus perform a somersault at all, so as to avoid all risk of soiling the peritoneum with the discharges from the diseased os and neck; or whether it is not advisable to remove the diseased cervix as a preliminary operation by amputation or with the curette; whether the broad ligaments should be ligated en masse, or in segments, or to rely on pressure forceps to be left in situ. whether the ovaries ought to be removed; whether the vaginal walls and peritoneal edges should be brought together with suture, or leave the vaginal wound unclosed; and whether a drain is to be used.

Mrs. Eliza $K-$, aged forty-six, was admitted into the Cancer Hospital on June 17th, 1887, being a patient sent to me from Birmingham by Dr. John W. Taylor, who had curetted and cauterised the os and cervix about three months previously at the Birmingham Hospital for Women and where she was at the time examined by Mr. Lawson Tait. The patient is a fairly well-nourished woman, the mother of one child aged twenty-four years, and had always enjoyed good health until about twelve months ago, when she had romiting of blood and violent pains across the pit of the stomach and back. Three months subsequently (Sept. 1886) a raginal discharge cam $\theta$ on, and pain, with difficulty in micturating, necessitated treatment under the care of Dr. John IT. Taylor, and in January he performed an operation on the urethra. Some six weeks later malignant disease of the os and cervix was discovered; for this she was examined, in conjunction with Dr. Taylor, by Mr. Lawson Tait, and had the os and cervix curetted and cauterised by Dr. Taylor. Recurrence of the disease showed itself about three weeks ago, for which Dr. Taylor advised kolpohysterectomy, and kindly sent her to me. The disease now occupies the stump and neck as far up, if not beyond, the os internum; walls of the vagina are sound. On examining with the two fingers in the rectum and the other hand over the pubes, the body is found larger than normal, more particulariy its left half; the organ is freely movable, and the broad ligaments appear healthy; no enlarged glands are to be felt. She has passed the menopause. There is no family history of cancer or of phthisis to be made out. Father died at seventy-nine; mother died at seventy-two, having had thirteen children. After a consultation with my colleagues, and having decided that removal of the uterus was justifiable, fully explaining the nature and risks of the operation to the patient, as also to her husband, and which they had had previously explained to them by Dr. Taylor, consent was given and the best wished for.

On June 23rd I proceeded to operate, assisted by my colleagues, Dr. Snow and Mr. Jessett. Dr. John W. Taylor came up from Birmingham and was present, as also Mr. Henry Reeves, and other visitors. The patient was placed in the lithotomy position, the bladder emptied, and vagina and parts douched with carbolised water; a duck-bill speculum in the posterior fourchette, aided by the fingers of my assistants, brought the parts well into view. Steadying the uterus by fixing a vulsellum in the cervix, the mucous membrane was incised all round, the anterior and posterior flaps reflected upwards, the bladderkept out of the way, and a segment pinched up laterally (first one side then the other), and a ligature passed through it with an aneurysm needle, so as to include the Inwer uterine vessels, was tied, and divided away. The peritoneum was entered both anteriorly and posteriorly, and the apertures enlarged by tearing; the two fingers of the right hand were passed up through the anterior opening and over the fundus, and then over the right broad ligament, which it was made to encircle. Now a silk thread was passed by means of a long well-curved aneurysm needle on the finger, until it encircled the broad ligament and insinuated down posteriorly; the thread was hooked out of the eye and the needle withdrawn; the broad ligament was gently drawn down and examined for absence of ureter. Feeling satisfied of its not being present, the ligature was tied. Tying the broad ligament en masse, close up to the ligature on its uterine side, I applied two pressure forceps as a guard, and, cutting the thread short, divided the parts away from the uterus with scissors. The pedicle receded together with the forceps; the uterus sidled down, presenting its right cornu ; the left-hand fingers now were passed in front and above the left broad ligament, followed by a silk thread, which was passed through the substance double. Having examined for absence of ureter and not observed, it was tied double and again encircled, clamped with pressure forceps and divided. The Fallopian tube was not included, and on bringing the uterus down, which was now free, the left ovary came down along with it, and on gently drawing, the Fallopian tube followed, when all was withdrawn; the Fallopian tube on the right side had been included in the pedicle, but now the right ovary was felt for and brought down, its attachment tied and severed, and it was got away. Parts around and within were douched, cleaned, and dried; there was no oozing of blood, and little blood was lost. The pressure forceps were all carefully taken off; no attempt at closing the vaginal or peritoneal wotind was made. Bladder and bowel and surrounding parts were finally examined, a glass drain, with its end rounded, but perforated, was inserted; this and the vulva was covered up with a large pad of salicylic wool and fixed by a T bandage; patient was removed to her bed in the general ward. The operation from first to last occupied one hour and twenty minutes.

In the evening, after operation, the pad and draw-sheet were found saturated with coloured water. Four ounces of urine were drawn off, and it was ordered to be drawn off by catheter when necessary. Temperature ranged between $96.8^{\circ}$ and $974^{\circ} \mathrm{F}$. The patient partook of ice only.

June 24th.-Patient passed a comfortable night; had no sickness. Five ounces of urine drawn off. Salicylic wool pad dry ; renewed. Iodoform dusted about and up the drainage tube; tube not interfered with. Pulse 74, intermittent; temperature (twenty-four hours) ranged between $98 \cdot 2^{\circ}$ and $100^{\circ} 2^{\circ}$

25th.-Slept at stretches of an hour; comfortable; no sickness. Was given six ounces of barley water during the night, and one drachm of essence of beef given twice; pad dry. Urine free. Temperature (twenty-four hours) ranged between $100^{\circ}$ and $994^{\circ}$.

26th.- - Very comfortable night; slept two hours at a time. Urine drawn off. Pulse feeble and intermittent. Pad dry. The drain taken out for the first time; only a small piece of shred found clung in a couple of the holes; its inner surface is coated with iodoform; no smell; clesned and replaced as before. Diet increased-fish, the essence of beef 